line, and we felt justified in extrapolating it to the values of mean grain spacing found in the cosmic ray plates.

In the accompanying table are the data from which the mass of the mesotron has been estimated. We have divided the tracks on the plates into groups, the range of variation of the mean grain spacing in each is given in ii $(a)$ and the resultant mean in ii $(b)$. The total length of tracks in each group is given in (iii), and their total deflection due only to multiple scattering in (iv). The mean energy of each group of mesotrons as calculated with the help of formula (1) is given in $\mathrm{v}(a)$ and of protons with the same mean grain spacing as obtained from the accompanying graph in $\mathrm{v}(b)$. The last column gives the calculated values of the mesotron mass. It will be seen that fairly consistent values of $\mu$ are obtained from $(A)$ and $(C)$ in plates exposed under air, while with those obtained from $(B)$ for plates exposed under $20 \mathrm{~cm}$. of water, the values are consistently high. This is understandable, since by collision of the high-energy neutrons present in the cosmic ray with the hydrogen atoms contained in the $20 \mathrm{~cm}$. layer of water, fast recoil protons are produced, and the scattering observed is due to a mixture of such protons with the mesotrons.

The method described above is a statistical one based upon a number of assumptions, averages and extrapolation. The presence of protons cannot be entirely excluded from such measurements. It is surprising, therefore, to find how the measured values of $\mu$ fall within the range of the best determina. tions by other methods ${ }^{6}$. It remains to be investigated whether the photographic method can be further improved into a precision method of determining the mass of $\mu$. The results obtained are important in other respects; it has enabled us to verify our previous surmise that the star-like tracks found in our photographic plates are due to secondary mesotron showers produced chiefly by cosmic ray neutrons. This and the presence in such showers of three-, four- and five-star tracks in approximately equal numbers are results which do not appear to be capable of interpretation in terms of existing theories.

A detailed account will appear in the Transactions of the Bose Institute.

${ }^{1}$ NATURE, 147, 240 (1941).

${ }^{2}$ Williams, E. J., Proc. Roy. Soc., A., 169, 539 (1939).

3 Wambacher, Phys. Z., 39, 888 (1939).

- Dunning, Phys. Rev., 45, 586 (1934); Bonner, Mott and Smith, Phys. Rev., 46, 258 (1934).

5 Blau, J. Phys. et Rad., 61 (1934).

${ }^{8}$ Bethe, Phys. Rev., 57, 260 (1940) estimates that the most reliable measured values of $\mu$ lie between 150 and $220 m_{0}$. When certain increased by at least 10 per cent.

\title{
FOOD AND INCOME
}

\section{By D. Caradog Jones \\ UNIVERSITY OF LIVERPOOL}

\begin{abstract}
A REPORT, published under the title "Food and the War", by the Edinburgh Branch of the Children's Nutrition Council*, gives an account of a study of the expenditure of a sample of families of the unskilled labouring class, made by voluntary workers during the period April-November, 1940. The object of the inquiry was to determine whether their incomes sufficed to purchase for these families an adequate diet as judged by two well-known standards, the first defined in the Report of the British Medical Association's Committee on Nutrition (1933), the second in the League of Nations Report on the Physiological Bases of Nutrition (1936, II B.4). Since the families were chosen solely on the ground of readiness to co-operate and lowness of income43 per cent had less than $50 \mathrm{~s}$. a week coming in and only 11 per cent had $£ 4$ or more-the main result of the investigation might be regarded as a foregone conclusion. Despite this fact and the small size of the sample studied, the figures and the inferences drawn from them are not without interest.

Of the 103 families visited 12 were on public assistance; in 38 the head was absent from home on war service, in 25 the wage earner was a labourer; the remainder are classed simply as "others". By means of a questionnaire particulars were obtained from all but two of these families as to their composition by sex and age and as to their expenditure on certain "fixed charges": rent and rates, lighting and heating, insurance and any regular payments to
\end{abstract}

*Children's Nutrition Council, 37 Esslemont Road, Edinburgh, 28 pp., $3 d$. a doctor. The total sum thus accounted for was in each case deducted from income and the balance was compared with the amount of money needed to feed the family adequately at 1940 prices according to the British Medical Association standard. It was discovered that 51 out of 72 families which supplied full information on this point, that is, 71 per cent, would have had insufficient money to pay for an adequate diet even if all the remaining balance had been spent on food. Actually, when the purchase of other necessities is brought into the account, only 10 per cent of the families sampled had enough money left to purchase an adequate diet. Using an American rating scale of somewhat doubtful accuracy a further estimate was made to the effect that the diets of 40 families out of 53 tested were less than 50 per cent adequate. The report itself gives tables, but the above are the broad conclusions.

Detailed records of their expenditure were kept for periods of one to three weeks by 76 families. Analysis of these budgets revealed that rather more than one half of the families sampled over-spent their income each week. This is on the perhaps doubtful assumption that all sources of income were disclosed to the investigators. Some ran up bills, paying a little off as they could and the debt growing bigger each week; others, in particular those with a member of the family in the Forces, received help from relatives.

In the majority of families the proportion of income spent on non-essentials was very small, but it increased as the income rose. Expenditure on necessities other than food included relatively large 
instalments towards the hire-purchase of clothes and furniture. The temptation to buy wardrobes is said to be strong on account of the lack of proper provision for hanging clothes in houses put up under recent schemes. One instance is quoted of instalments paid by the same family on three wardrobes in two years : two were removed owing to failure to continue the weekly payments. About three out of every four families investigated also paid regular premiums to meet the cost of burial, in some cases amounting to more than $7 s$. a week. This is a serious drain on slender resources-enough to "pay for a funeral every year".

Returning to the main theme of the inquiry, the writers suggest that, apart from education in regard to the value and preparation of different foods, much might be done to solve the diet deficiency problems raised in this study by a wide extension of cornmunal feeding, of the national milk scheme, and of all social services relating to food.

\section{USE OF GLASSES AS AN AID TO VISION}

\section{By R. WEATHERALL Eton College}

\begin{abstract}
$\mathrm{A}^{\mathrm{s}}$ $\mathrm{S}$ part of an investigation to discover whether physical defects among children increase with age, M. V. Marshall organized a survey of the use of glasses by children attending school in a representative American city. ${ }^{1}$ In all, the survey covers 8,204 children ranging in age from kindergarten to the twelfth grade; that is, 5-17 years. The results show an almost uninterrupted increase in the use of glasses, from $2 \cdot 7$ per cent among the youngest, to $15 \cdot 7$ per cent around the age of twelve, and 23.7 per cent by the time the pupils are leaving school. An additional proportion of the children, ranging between 2 per cent and 7.5 per cent, had been advised to wear glasses, but were not doing so.

Children do not take kindly to wearing glasses when they first begin to take an active part in school games, and when they become conscious of their own personal appearance. Allowing for such personal factors, there are unexplained checks in the use of glasses around the ages of ten and fifteen. Also,
\end{abstract}

personal factors alone can scarcely explain the wide discrepaney in the separate figures for boys and girls. Between the ages of twelve and seventeen the proportion of boys wearing glasses varies irregularly between 12 and 18 per cent, while for the same agegroups the girls show an increase from 17.7 to $32 \cdot 8$ per cent.

Altogether, the figures are striking enough. They show clearly that the need for glasses increases rapidly during a pupil's school life, so that by the age of sixteen about 1 in 7 of the boys, and 1 in 3 of the girls, are using artificial aids to vision. Even so, it is very probable that a still higher proportion of these children must be considered as having eyesight below normal. The figures revealed by this survey agree fairly well with those obtained by a smaller one which I carried out on boys attending a school in England. They give some measure of the magnitude of the problem of defective eyesight at the present time.

${ }^{2}$ School and Society, 53, No. 1375 (1941).

\section{FATIGUE TESTS OF WELDED JOINTS}

$\mathrm{T}$ HE publication by the University of Illinois Engineering Experiment Station of the results and conclusions derived from an investigation carried out there on welded joints in structural steel plates is but the first instalment or progress report of the proceedings*.

The primary object of those responsible was to obtain reliable information on which to base specifications governing the design of welded structural members subjected to reversed or pulsating stresses. The lack of knowledge of the fatigue strength of welded joints has been the principal deterrent to their adoption in the fabrication of bridges, and it was clear that tests on the largest practicable scale would have to be made before this method of construction could be placed on a satisfactory and reliable basis. Realizing this, the Welding Research Committee of the Engineering Foundation organized

* University of Illinois Engineering Experiment Station. Bulletin Series No. 327 : Fatigue Tests of Welded Joints in Structural Stee Plates. By Wilbur M. Wilson, Walter H. Bruckner, John V. Coombe and Richard A. Wilde. Pp. 86. (Urbana, IIl. U. Un. a special committee representative of all engineering interests to plan and carry out the work.

As used in this report, the term fatigue strength of a member refers to the maximum stress in the stress cycle which caused its failure at a stated number of cycles when the ratio of the minimum to the maximum stress had a stated value. While it is not possible to specify the stress which will cause failure at a predetermined number of cycles, it was practicable to estimate the stress cycle which would disrupt the specimen at the desired stage in the test. This was the procedure adopted and three kinds of cycle were used : (1) from a tensile stress to an equal compressive stress ; (2) from zero stress to a maximum tensile stress ; (3) from a maximum tensile stress to a minimum tensile stress of half the value. These gave ratios $r$, of $-1,0$ and +0.5 respectively, and for each value of $r$, seven identical specimens were tested: three so as to fail at 100,000 cycles, and three at 2,000,000 cycles, the seventh being a spare to be tested as desired after the other six tests had been completed. 